Article

\title{
Prediction of Particle-Collection Efficiency for Vacuum-Blowing Cleaning System Based on Operational Conditions
}

\author{
Yuan $\mathrm{Xi}^{1,2,3}$, Yan Dai ${ }^{1,3, * \mathbb{C}}$, Xi-long Zhang ${ }^{4, *}$ and Xing Zhang ${ }^{5}$ \\ 1 Panjin Institute of Industrial Technology, R\&D Center of Membrane Science and Technology, \\ School of Chemical Engineering, Dalian University of Technology, Panjin 124221, China; \\ xiyuan@dlut.edu.cn \\ 2 State Key Laboratory of Fluorine Containing Functiona, Shandong Huaxia Shenzhou New Material Co.Ltd., \\ Zibo 255000, China \\ 3 Liaoning Key Laboratory of Chemical Additive Synthesis and Separation, Panjin Institute of Industrial \\ Technology, Dalian University of Technology, Panjin 124221, China \\ 4 School of Mechanical\&Automotive Engineering, Qingdao University of Technology, Qingdao 266071, China \\ 5 Department of Petroleum Engineering, Faculty of Petroleum, China University of Petroleum-Beijing at Karamay, \\ Karamay 834000, China; zhangxing@cupk.edu.cn \\ * Correspondence: daiyan@dlut.edu.cn (Y.D.); zhangxilong@qut.edu.cn (X.-1.Z.)
}

Received: 4 June 2020; Accepted: 7 July 2020; Published: 9 July 2020

\begin{abstract}
The dust-collection system, as the core of a sweeper vehicle, directly inhales dust particles on the pavement. The influence of variable operational conditions on particle-separation performance was investigated using computational fluid dynamics (CFD) Euler-Lagrange multiphase model. The particle-separation performance efficiency and retention time were used to evaluate the dust-collection efficiency. The uniform design (UD) and multiple regression analysis (MRA) methods were employed to predict and optimize the effects of reverse-blowing flow rate, pressure drop, and traveling speed on separation efficiency. The results indicated that the dust-collection performance initially increased and then decreased with increasing reverse-blowing flow rate. As the pressure drop increased, there was an increase in total dust-collection efficiency. However, the efficiency decreased with increasing traveling speed. The regression model showed that the proposed approach was able to predict the particle collection efficiency accurately. In addition, the optimum operational conditions were obtained, namely a reverse-blowing flow rate of $2100 \mathrm{~m}^{3} / \mathrm{h}$, a traveling speed of $5 \mathrm{~km} / \mathrm{h}$, and a pressure drop of $2400 \mathrm{~Pa}$. The maximum particle-separation efficiency was $99.10 \%$, which showed good agreement with the experimental results.
\end{abstract}

Keywords: vacuum-blowing cleaning system; CFD; separation efficiency; operational condition; uniform design

\section{Introduction}

Particulate pollution is becoming more and more serious with the continuous improvement of the urbanization process, and mainly originates from road dust resuspension [1,2]. Particulate pollution poses a great threat to human health, easily causing dizziness and mental and cardio-cerebral vascular diseases [3]. Moreover, it may also cause lung cancer in people who spend a long time in polluted environments [4,5]. Many local authorities consequently use sweeper vehicle for pollution prevention, and the method has proven to be very effective.

The dust collection system is the core of the sweeper vehicle. It directly inhales dust particles on the pavement and determines the particle collection efficiency. Many methods have been proposed to 
improve the particle collection efficiency. Spatial and chemical patterns of road-deposited sediments have been evaluated through testing experiments [2], which laid a good foundation for designing dust-collection systems. Chen et al. [6] found that adding a wing plate improved the particle collection efficiency in a trial production prototype. This method not only takes a long time, but also does not take into account the status and trajectories of particle flow. Daichin [7] used particle image velocimetry (PIV) techniques to observe the variations of flow fields. He reported that the trench height and shape of the connection chamber had a great influence on working efficiency.

The flow field within a dust-collection system has high turbulence and reverse flow. It is hard to analyze particle collection performance through experiments alone. Thus, with the rapid development of computer technology, computational fluid dynamics (CFD) methods are becoming widely used in studies of the dust-collection systems of sweeper vehicles [8,9]. The flow field characteristics of the dust-collection system and the filter system were analyzed by Zeng [10] and Xu [11], respectively. The structures were optimized according to the gas-phase numerical simulation results. These works proved that the CFD method is useful. However, the practical working process is a gas-solid two-phase flow [2,12]. Analysis of the gas phase alone, neglecting the influence of solid particles, cannot determine the flow properties and removal efficiency of particles. Wu et al. $[13,14]$ numerically analyzed particle trajectories with gas-solid flow and found that the inclination angle of the rear edge wall and the pressure drop were major influencing factors. The optimal angle and pressure drop were $135^{\circ}$ and $2400 \mathrm{~Pa}$, respectively. Liu et al. [15] designed a new type of structure utilizing the tornado principle based on gas-solid flow. The results showed that the influences of different structure parameters and extended domains had the corresponding threshold. In our previous published papers, we designed a vacuum-blowing cleaning system with an $L$-shape cavity [16,17], utilizing the positive and negative pressure mixed-delivery theory. The vacuum-blowing cleaning system had lower energy consumption and a larger working area, compared with traditional vacuum-type systems (Figure 1).

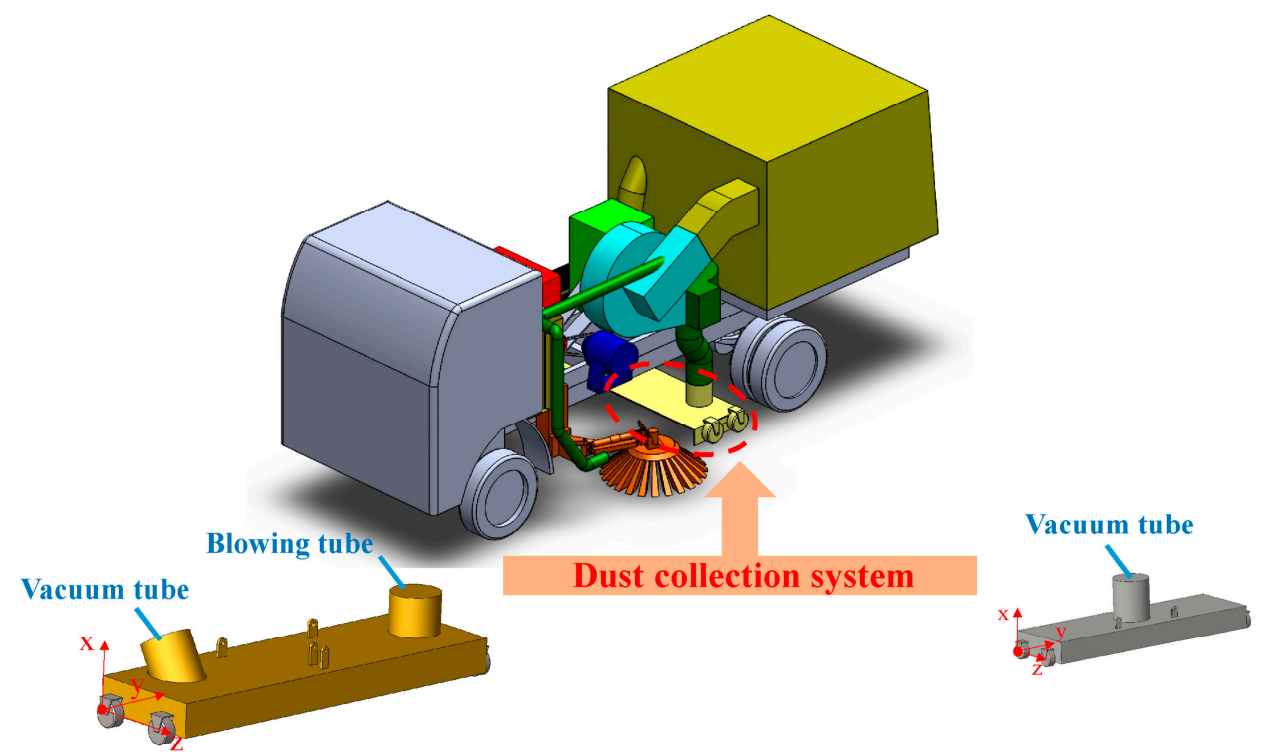

(a) Vacuum-blowing type

(b) Traditional vacuum type

Figure 1. Dust-collection system of sweeper vehicles.

The flow patterns depend on the type of structural change. Therefore, the particle collection efficiency can be improved if the flow pattern is smooth. Another way to improve particle collection efficiency is to change the operational conditions. Wu et al. [14] numerically studied particle collection performance under different operational conditions, such as traveling speed and pressure drop, and finally proposed a trade-off suggestion. There have been relatively fewer scientific reports and analyses of vacuum-blowing cleaning systems. According to these investigations, the traditional vacuum-type 
system provides negative pressure only. However, the vacuum-blowing type uses both negative and positive pressure, so the particle behavior in the mixed-pressure field is more complicated, and detailed design guidelines for different operational conditions are not available. More importantly, the interactions of influencing factors should not be neglected. Only by understanding the influence of the operational conditions can we control particle trajectories.

In this paper, the interplay between operational conditions was investigated, in order to predict separation efficiency accurately and match operating parameters rapidly. The total dust-collection efficiency, the grade dust-collection efficiency, and average retention time were subsequently calculated. At the same time, a mathematical regression model, using total dust-collection efficiency as the evaluating parameter of the particle-separation performance, was established. Finally, the rationality of the numerical simulation was verified via experiments.

\section{Numerical Models}

\subsection{CFD Model Construction}

A vacuum-blowing cleaning system is composed of the supporting wheel, the hoisting lug, the front damper, and the dust suction pipeline. A three-dimensional model was built using Creo 3.0, as shown in Figure 2. The vacuum-blowing cleaning system designed in our previous published papers $[16,17]$ was used in this study. The structural parameters are summarized in Table 1.

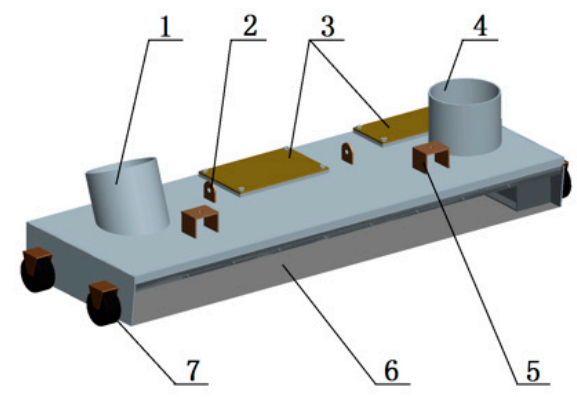

1-Suction inlet; 2-Lifting lug; 3-Dust removal cover plate; 4-Reverse-jet; 5-Base plate 6-Front damper; 7-Return roller

Figure 2. Vacuum-blowing cleaning system.

Table 1. Physical Model Parameters of Computational Domain.

\begin{tabular}{cc}
\hline Parameter & Value \\
\hline length, $L(\mathrm{~mm})$ & 1400 \\
width, $B(\mathrm{~mm})$ & 540 \\
thickness, $H(\mathrm{~mm})$ & 150 \\
front damper angle, $\alpha\left(^{\circ}\right)$ & 105 \\
suction inlet inclination angle, $\beta\left(^{\circ}\right)$ & 110 \\
suction inlet diameter, $D_{1}(\mathrm{~mm})$ & 200 \\
reverse-jet diameter, $D_{2}(\mathrm{~mm})$ & 200 \\
ground clearance, $\delta(\mathrm{mm})$ & 10 \\
length of the expansion areas, $l_{e a}(\mathrm{~mm})$ & 180 \\
height of the expansion areas, $h_{e a}(\mathrm{~mm})$ & 150 \\
slant angle of the expansion areas, $\theta_{e a}\left({ }^{\circ}\right)$ & 55 \\
\hline
\end{tabular}




\subsection{Mathematical Model}

The airflow through the vacuum-blowing cleaning system was calculated using governing equations. Although the airflow was turbulent at high Reynolds numbers, it was not a strong rotational flow. In view of the incompressible and steady flow, the Reynolds-averaged Navier-Stokes governing equations can be written as

$$
\text { Continuity : } \frac{\partial u_{i}}{\partial x_{i}}=0
$$

where $u_{i}$ is the airflow velocity.

$$
\text { Momentum : } \frac{\partial}{\partial x_{j}}\left(\rho u_{i} u_{j}\right)=-\frac{\partial P}{\partial x_{i}}+\frac{\partial}{\partial x_{j}}\left(\mu \frac{\partial u_{i}}{\partial x_{j}}+\mathrm{T}_{i j}\right)+\rho g_{i}
$$

where $\rho, \mathrm{P}$, and $\mu$ are the fluid density, pressure, and viscosity, respectively. $g_{\mathrm{i}}$ is the gravity acceleration. $\mathrm{T}_{i j}=-\rho \overline{u_{i}{ }^{\prime} u_{j}{ }^{\prime}}$ is the Reynolds stress.

The selection of turbulence models for prediction of flow field characteristics depends on the physical model used. The $k-\varepsilon$ model is widely used for dust-collection and sweeper vehicles $[8,13,17]$, and it can provide accurate predictions for complex flows. The $k-\varepsilon$ equation takes the following form.

$$
\begin{gathered}
\rho \frac{d k}{d t}=\frac{\partial}{\partial_{x j}}\left[\left(\mu+\frac{\varepsilon_{m}}{\sigma_{k}}\right) \frac{\partial k}{\partial x j}\right]+G_{k}-\rho \varepsilon \\
\rho \frac{d \varepsilon}{d t}=\frac{\partial}{\partial_{x j}}\left[\left(\mu+\frac{\varepsilon_{m}}{\sigma_{\varepsilon}}\right) \frac{\partial k}{\partial x j}\right]+C_{1 \varepsilon} \frac{\varepsilon}{k} G_{k}-C_{2 \varepsilon} \rho \frac{\varepsilon^{2}}{k}
\end{gathered}
$$

where $G_{k}=-\rho \overline{u_{i}^{\prime} u_{j}^{\prime}} \frac{\partial \overline{u_{i}}}{\partial j^{\prime}}$, and the constants are $\sigma_{k}=1.0, C_{1 \varepsilon}=1.44, C_{2 \varepsilon}=1.92, \sigma_{\varepsilon}=1.3$ [15].

The Euler-Lagrange approach was used to predict the particles' trajectories within the vacuum-blowing cleaning system. The airflow and particles were treated as continuous and disposed phases, respectively. The continuous phases were described with Navier-Stokes governing equations. A discrete-phase model (DPM) was used to describe the physical properties of the particles because the volume fraction was less than $10 \%[18,19]$. According to Newton's Second Law, the equilibrium equation was expressed as follows.

$$
m_{p} \frac{d u_{p}}{d t}=F_{D}+F_{g}+F_{s}
$$

where $m_{p}$ is the mass of the particle, $u_{p}$ is velocity, $F_{D}$ is the cohesive force, $F_{g}$ is gravity, and $F_{S}$ is lifting force.

$$
\begin{gathered}
F_{D}=\frac{18 \mu}{\rho_{\mathrm{p}} d_{\mathrm{p}}^{2}} \frac{C_{\mathrm{D}} \operatorname{Re}}{24} m_{\mathrm{p}}\left(u-u_{\mathrm{p}}\right) \\
F_{\mathrm{g}}=m_{\mathrm{p}}\left(1-\rho / \rho_{\mathrm{g}}\right) g \\
F_{\mathrm{S}}=\frac{2 K v^{1 / 2} \rho d_{i j}}{\rho_{\mathrm{p}} d_{\mathrm{p}}\left(d_{l k} d_{k l}\right)^{1 / 4}}\left(u-u_{\mathrm{p}}\right)
\end{gathered}
$$

where $\rho_{\mathrm{p}}$ and $d_{\mathrm{p}}$ are the density and diameter of the particle, respectively. $C_{\mathrm{D}}$ is the drag coefficient. $v$ is the kinematic viscosity, and $d_{i j}$ is the deformation tensor, and the constant is $K=2.594[20,21]$.

\subsection{Boundary Conditions and Solution Controls}

The studied vacuum-blowing cleaning system worked under both positive and negative pressure. There were four narrow slots between the bottom edge and the ground, which we called "ground clearance". The flow rate, velocity, etc. were unknown because they were measured at the interface between internal and external flow field. To find the fully developed turbulence, expansion areas 
(see Figure 3) were used $[8,13,14,16,22]$. The slant angle of the expansion areas was $55^{\circ}$. The length of the expansion areas was $180 \mathrm{~mm}$. The height of the expansion areas was the same as the thickness of the vacuum-blowing cleaning system $[16,17,22]$.

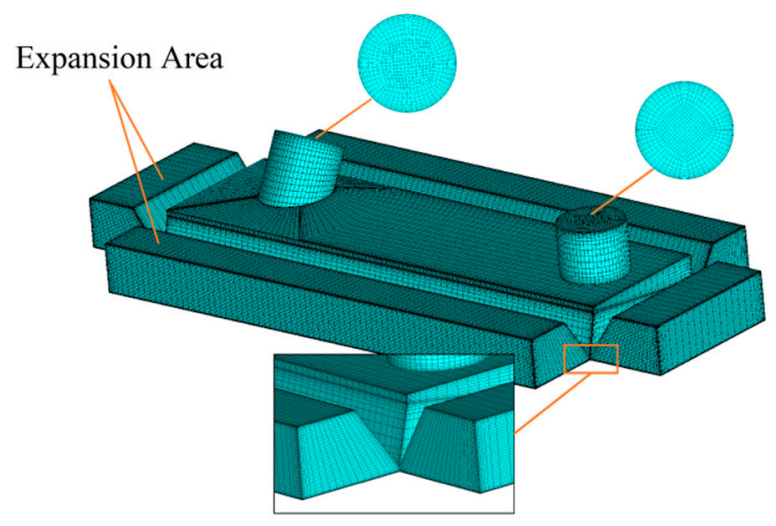

Figure 3. Computational mesh.

Fluent 14.5 was used for the flow field calculation. The suction inlet, reverse-jet, expansion area, and other boundary conditions were set as the pressure outlet, velocity inlet, pressure inlet, and wall surface, respectively. The bottom surface of the 3D numerical model was defined as the non-slipping wall, and the other surfaces were defined as moving walls for simulation of the driving status. It was assumed that at each wall with the condition "reflect", only particles with the condition "escape" would be exported (at the suction inlet), to set the boundary conditions. The finite-volume method and standard $k-\varepsilon[8,13,17]$ turbulence model were applied. In addition, an incompressible steady-state solution method was selected for calculation. The second-order upwind was used as an interpolation function, and the pressure-velocity coupling was done using SIMPLE algorithm.

For the simulation of particle dispersion in a gas-particle two-phase flow, a discrete-phase model (DPM) was used to describe the physical properties of the particles, because the volume fraction was less than $10 \%[18,19]$. Turbulent dispersion with stochastic tracking was utilized. The discrete random walk model was also used during simulations. Meanwhile, steady particle tracking was adopted for particle treatment. The restitution coefficient was the ratio of the relative velocity of two elastic bodies after rebounding to velocity before impact. There were two restitution coefficients for the walls with the condition "reflect", namely the normal and tangential restitution coefficients $[23,24]$. The restitution coefficients were utilized for particle-wall interaction in this paper, and the collisions were assumed to be inelastic. The particles were treated as spherical. The diameter, particle density, restitution coefficients, etc. were set as the experimental data reported by $\mathrm{Wu}[13,14]$. The vacuum-blowing cleaning system moved forward when it worked. Therefore, the particles were assumed to be injected from the bottom surface of the front expansion area. The main simulation parameters are summarized and listed in Table 2.

Table 2. Simulation Parameters.

\begin{tabular}{cccc}
\hline Parameter & Value & Parameter & Value \\
\hline Near-Wall treatment & Scalable wall function & particle model & Rosin-Rammler \\
TKE prandtl number & 1 & total flow rate, $q_{\mathrm{m}}\left(\mathrm{kg} \cdot \mathrm{s}^{-1}\right)$ & 0.5 \\
TDR prandtl number & 1.3 & gas density, $\rho_{\mathrm{g}}\left(\mathrm{kg} \cdot \mathrm{m}^{-3}\right)$ & \\
Energy prandtl number & 0.85 & particle density, $\rho_{\mathrm{p}}\left(\mathrm{kg} \cdot \mathrm{m}^{-3}\right)$ & 1.225 \\
Wall prandtl number & 0.85 & distribution density, $\rho_{\mathrm{d}}\left(\mathrm{kg} \cdot \mathrm{m}^{-2}\right)$ & 2500 \\
coefficient, $C_{\text {mu }}$ & 0.89 & particle mean diameter, $d_{\mathrm{m}}(\mu \mathrm{m})$ & 0.15 \\
coefficient, $C_{1 \varepsilon}$ & 1.46 & spread parameter, $n$ & 8.95 \\
constant, $C_{2 \varepsilon}$ & 1.89 & normal restitution coefficient, $e_{\text {normal }}$ & 0.95 \\
constant, $\delta_{\varepsilon}$ & 1.4 & tangential restitution coefficient, $e_{\text {tangential }}$ & 0.85 \\
\hline
\end{tabular}




\subsection{Grid Generation}

Each portion was meshed with structured grids using integrated computer engineering and manufacturing (ICEM) code, after decomposing the complex geometry into several computational portions (see Figure 3). In view of the high accuracy and efficiency of numerical simulation, the grid generation was vital.

The $y+$ value is a non-dimensional distance to the wall for a wall-bounded flow, and it is commonly used in boundary layer theory and in defining the law of the wall. The $y+$ value is commonly found in turbulence problems. The solution of turbulence problems is more dependent on grid generation. The $y+$ value can be defined as follows.

$$
y+=\frac{u_{*} y}{v}
$$

where $u_{*}$ is the friction velocity at the nearest wall, $y$ is the distance to the nearest wall, and $v$ is the local kinematic viscosity.

Several simulations were performed with $y+$ values of $3,5,10,30,50,80$, and 100 on the original machine, in order to verify the grid independence. The influence of $y+$ on the volume flow (at the reverse-jet) was employed to ensure the higher precision of the calculation (see Figure 4). The relative error was lower than $10 \%$ when $y+$ was less than 100 , which meant that the grid independence met the requirements. Maintaining a low relative error was crucial in order to ensure high accuracy. Therefore, the grid $y+$ value was set as 3 for the following mesh generation. Finally, the computational model was meshed with a total of 413,201 cells, and scalable wall functions were used near the wall.

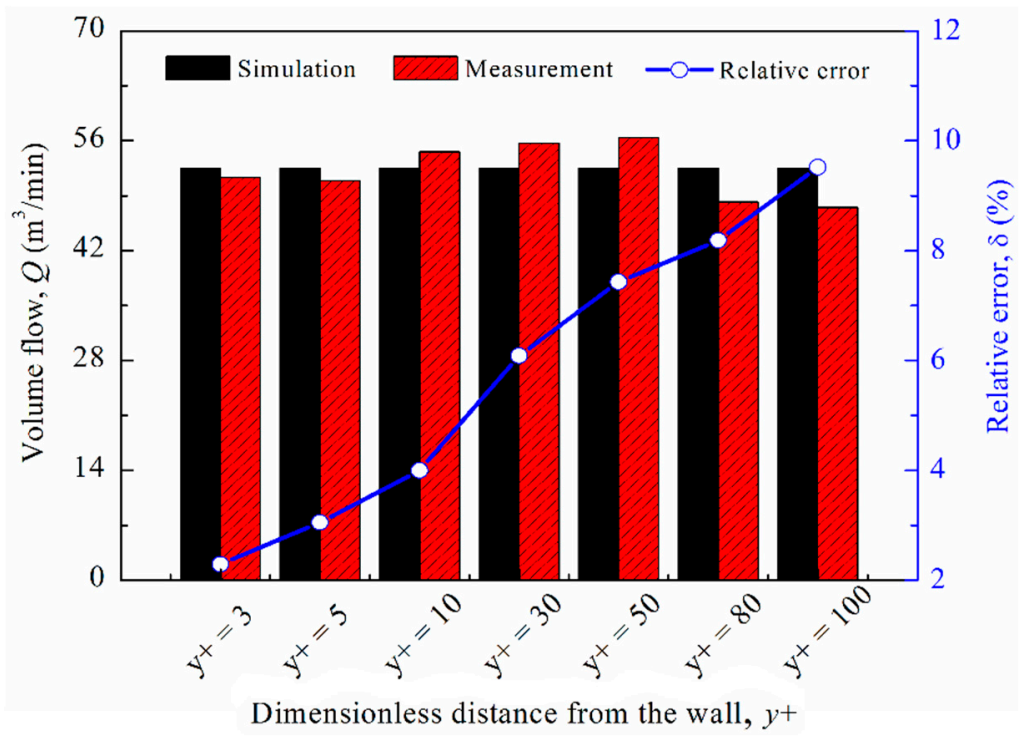

Figure 4. Influence of $y+$ on the volume flow.

\section{Results and Discussion}

\subsection{Influence of Reverse-Blowing Flow Rate on the Separation Efficiency}

The separation efficiency included the total and grade dust-collection efficiency. The total dust-collection efficiency was the ratio of the amount of trapped dust to the amount of dust entering the device. It was calculated by monitoring the number of particles. The particles were injected through the bottom surface of the front expansion area, while the particles escaped through the suction inlet surface. Therefore, we could find the total dust-collection efficiency according to the particle number [25]. The grade dust-collection efficiency was the removal efficiency of dust of a certain particle diameter. It was calculated using the same method as the total dust-collection efficiency. 
The change in the total dust-collection efficiency under different reverse-blowing flow rates is shown in Figure 5. As the flow rate increased, the total dust-collection efficiency first increased and then decreased. When the flow rate was less than $2172 \mathrm{~m}^{3} / \mathrm{h}$, the total dust-collection efficiency increased gradually from $69.20 \%$ to $97.35 \%$. Subsequently, the total dust-collection efficiency decreased sharply from $97.35 \%$ to $16.31 \%$.

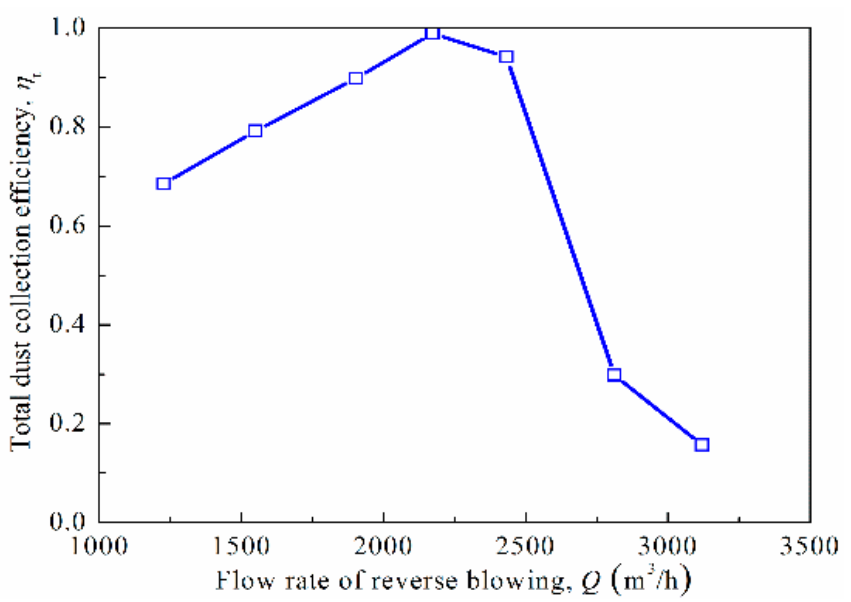

Figure 5. Influence of reverse-blowing flow rate on the total dust-collection efficiency.

When the flow rate was low, the particles were easily blown near the suction inlet. Therefore, the particles could be picked up. For higher flow rates, firstly, the movement of the particles from reverse-blowing outlet to dust suction port was affected. Secondly, excessive flow rates gave the particles more kinetic energy, especially for particles with relatively large mass, of which the inertia could not be ignored. Take the highest and lowest total dust efficiencies, for example. The particle velocities and trajectories under different reverse-blowing flow rates are shown in Figure 6. We saw that the inhaled dust would be leaked under higher reverse-blowing flow rates.

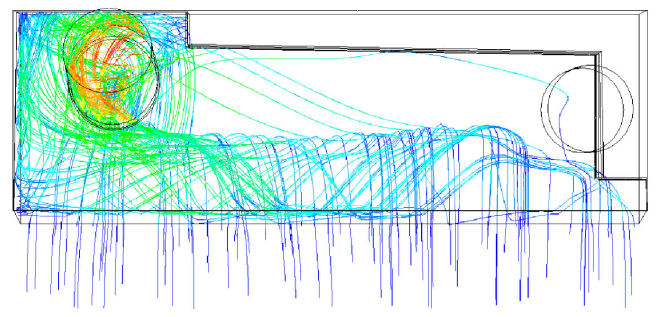

(a) $Q_{\mathrm{R}}=2172 \mathrm{~m}^{3} / \mathrm{h}$

Velocity Magnitude

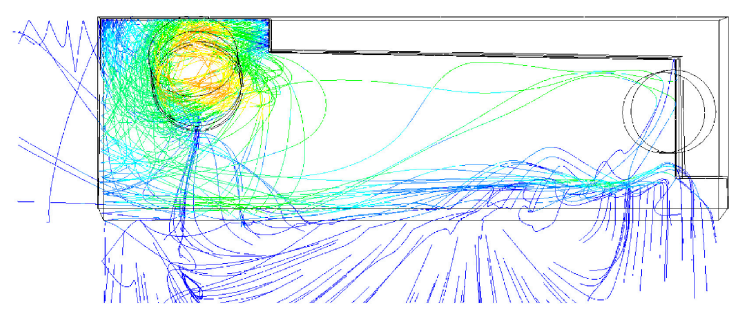

(b) $Q_{\mathrm{R}}=3120 \mathrm{~m}^{3} / \mathrm{h}$

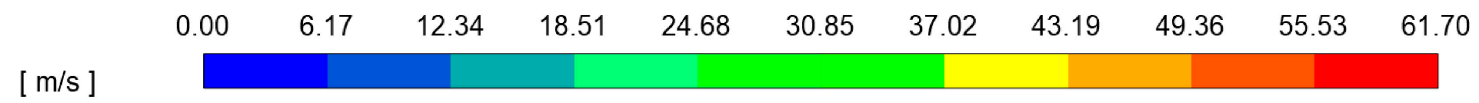

Figure 6. Particle velocity and trajectory of under different reverse-blowing flow rates: (a) reverse-blowing flow rate is $2172 \mathrm{~m}^{3} / \mathrm{h}$; (b) reverse-blowing flow rate is $3120 \mathrm{~m}^{3} / \mathrm{h}$.

Figure 7 illustrates the grade dust-collection efficiency for different particle sizes. Under circumstance of different particle diameter for same reverse-blowing flow rate, the grade dust-collection efficiency decreased, on the whole, with the increase of the particle diameter from $45 \mu \mathrm{m}$ to $152 \mu \mathrm{m}$. However, under circumstance of different reverse-blowing flow rates for the same particle diameter, the grade dust-collection efficiency increased with increasing particle diameter from $1227 \mathrm{~m}^{3} / \mathrm{h}$ to $2172 \mathrm{~m}^{3} / \mathrm{h}$. However, it decreased rapidly after $2172 \mathrm{~m}^{3} / \mathrm{h}$. The grade dust-collection efficiency was determined by the particle size, and differences in dust particle dispersion also contributed to 
the difference. The particles obtained more kinetic energy, especially the larger particles, which could cause the inhaled particles to overflow from the side walls (see Figure 6b), which reduced the grade dust-collection efficiency.

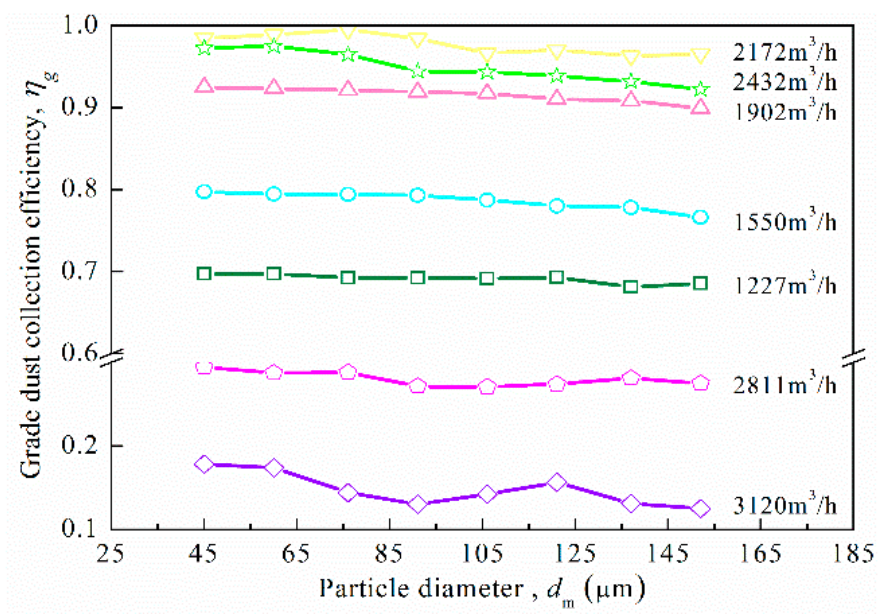

Figure 7. Influence of reverse-blowing flow rate on the grade dust-collection efficiency.

The average residence time is often used to evaluate the dynamic characteristic of particles. It was defined as how long a particle took to move from the injection surface to the suction inlet surface. The average residence times of the particle sizes under different reverse-blowing flow rates are shown in Figure 8. Particles of different sizes had different properties under different flow rates, such as the ability of diffusion, turbulence, and wind speed; thus, different average residence times were presented. In the case of the same flow rate, the average residence time was affected slightly by the changing of particle size. With the change of particle size from 45 to $152 \mu \mathrm{m}$, the longest average residence time and the shortest average residence differed by $0.183 \mathrm{~s}$ (i.e., $1902 \mathrm{~m}^{3} / \mathrm{h}$ ). The average residence time was mainly related to particle size, trajectory, and momentum. The results indicated that the lower the residence time, the higher the dust-collection efficiency was.

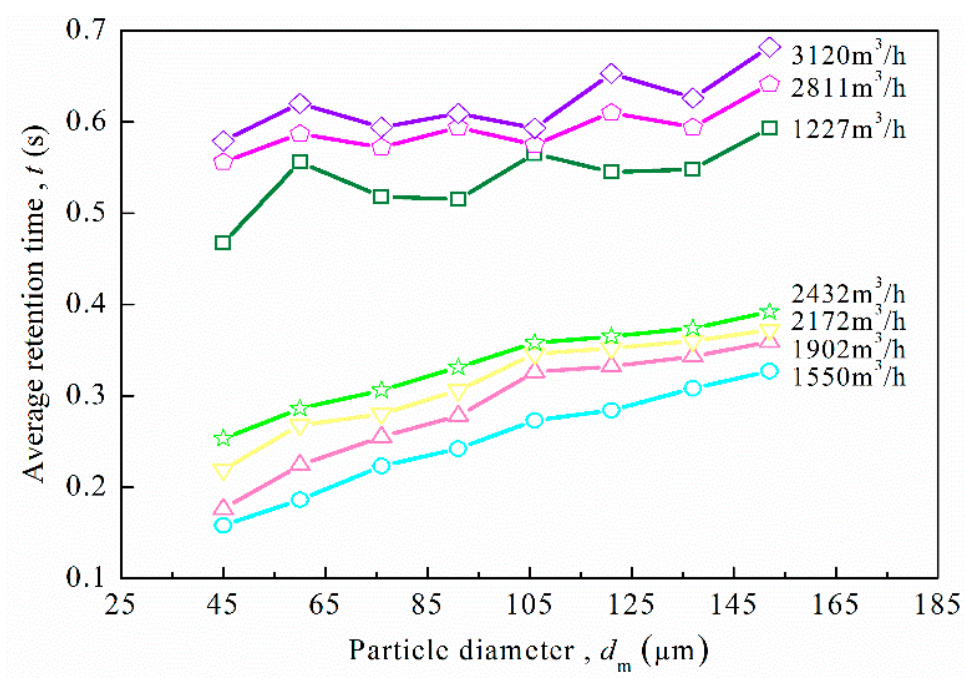

Figure 8. Influence of reverse-blowing flow rate on the average retention time. 


\subsection{Influence of Pressure Drop on the Separation Efficiency}

The pressure drop was the pressure difference between the suction inlet surface and expansion-area inlet surface [13,14]. The simulation was performed under a steady-state pressure drop. The expansion area was connected to the atmosphere and its pressure value was the standard atmosphere value. Figure 9 shows the relationship between the pressure drop and the total dust-collection efficiency. As the pressure drop increased, there was an increase in total dust-collection efficiency. The efficiency increased from $68.11 \%$ to $86.15 \%$ when the pressure changed from 1400 to $2000 \mathrm{~Pa}$. When the pressure drop was finally increased from 2600 to $2900 \mathrm{~Pa}$, the total dust-collection efficiency did not change significantly.

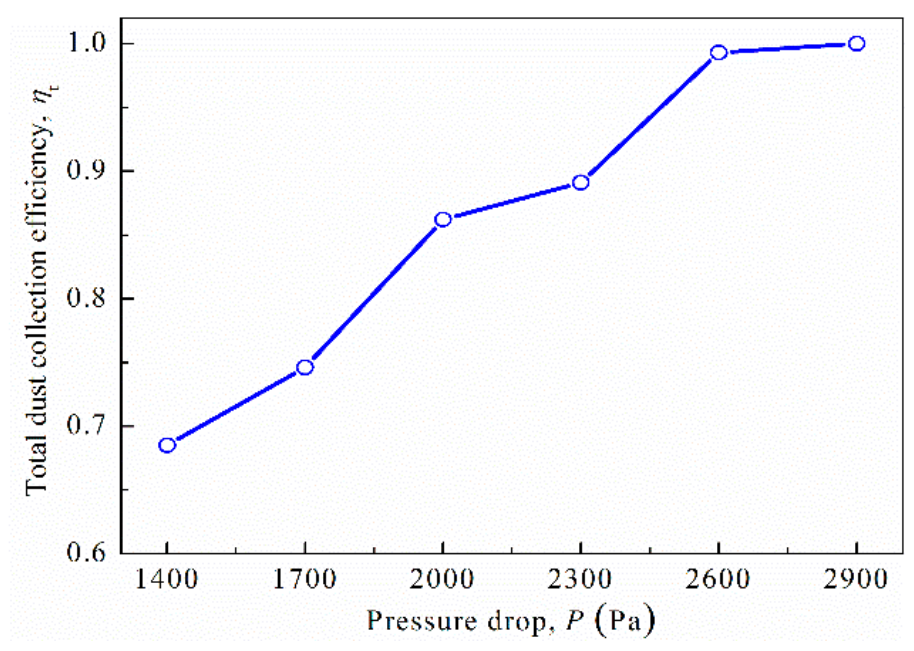

Figure 9. Influence of pressure drop on the separation efficiency.

The internal airflow velocity was increased with increasing pressure drop without changing the structure. Therefore, the particles obtained more kinetic energy, and the total dust-collection efficiency was improved. The high-speed airflow carried the particles to the collectors. The flow rate increased, which meant that the loss along the path was increased. The loss was only proportional to the internal flow velocity after fixing the structure of the flow [26]. Therefore, when the pressure drop was greater than $2600 \mathrm{~Pa}$, a dynamic balance was realized, owing to the internal loss of the path and the increase of the pressure drop. The loss was approximately equal to the offset. The change of velocity at the intake surface was not obvious, and the dust removal efficiency remained basically unchanged.

The influence of pressure drop on the grade dust-collection efficiency is shown in Figure 10. For a given particle pressure drop, the grade efficiency decreased when the particle size increased from $45 \mu \mathrm{m}$ to $152 \mu \mathrm{m}$ (for example, a pressure drop of 2900 Pa corresponded to a 5.4\% decrease). Similarly, for the same particle size, the grade efficiency increased with increasing pressure drop. The most significant improvement (from $59.11 \%$ to $94.61 \%$ ) occurred for pressure drops ranging from $1400 \mathrm{~Pa}$ to $2900 \mathrm{~Pa}$, and a given particle diameter of $152 \mu \mathrm{m}$.

The influence of pressure drop on the average retention time was very similar to that of grade dust-collection efficiency (see Figure 11). For a given particle pressure drop, the average retention time increased when the particle size increased from $45 \mu \mathrm{m}$ to $152 \mu \mathrm{m}$ (for example, a pressure drop of $1400 \mathrm{~Pa}$ corresponded to a $0.751 \mathrm{~s}$ increase). Similarly, for the same particle size, the average retention time decreased with increasing pressure drop. The most significant improvement (from $0.751 \mathrm{~s}$ to $0.332 \mathrm{~s}$ ) occurred for pressure drops ranging from $1400 \mathrm{~Pa}$ to $2900 \mathrm{~Pa}$, and a given particle diameter of $152 \mu \mathrm{m}$. The smaller diameter particles had good follow ability and were relatively less affected by gas flow rate. However, larger-diameter particles also required more momentum and airflow lifting force due to their own inertia. Although a single particle had a small influence on the internal characteristic, for the amount of the particles, the solid particle phase had an effect on the gas phase. 


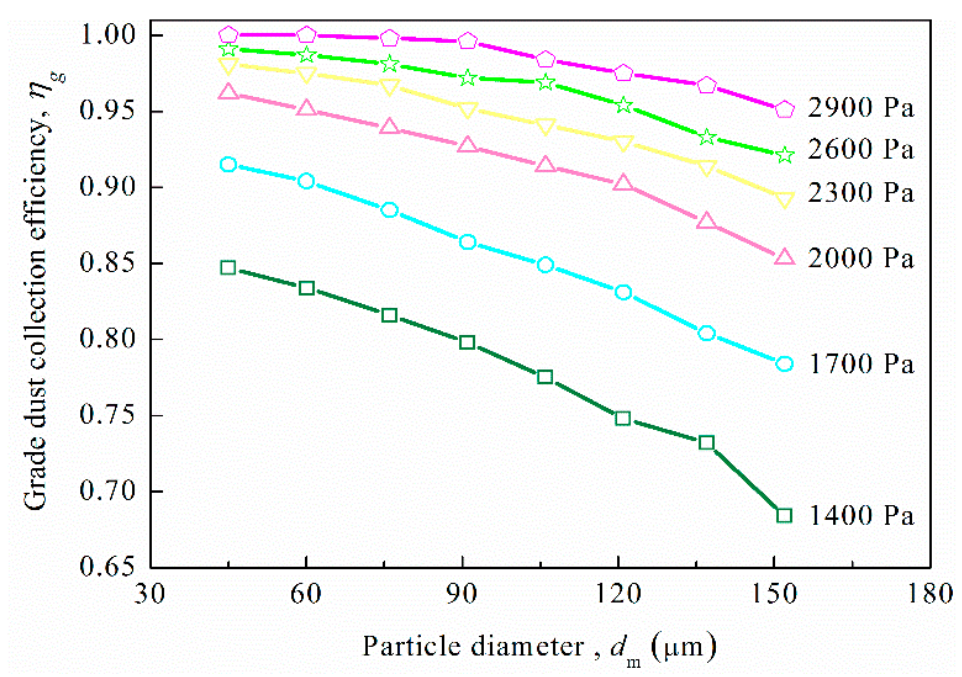

Figure 10. Influence of pressure drop on the grade dust-collection efficiency.

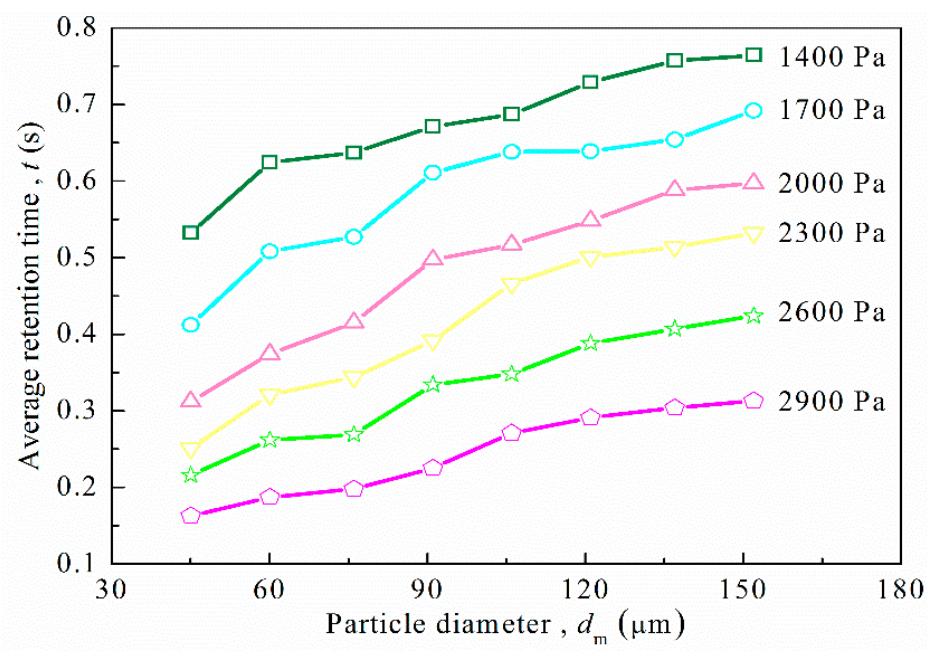

Figure 11. Influence of pressure drop on the average retention time.

\subsection{Influence of Traveling Speed on the Separation Efficiency}

The influence relationship between the speed and the total dust-collection efficiency is shown in Figure 12. As the traveling speed increased, there was a decrease in total dust-collection efficiency. The efficiency decreased from $96.97 \%$ to $79.01 \%$ when the speed changed from $5 \mathrm{~km} / \mathrm{h}$ to $14 \mathrm{~km} / \mathrm{h}$. Firstly, the gradually increasing vehicle speed made the relative speed between the reverse-blowing pickup mouth and the ground particles increase, which made the particles of different sizes on the ground move towards the suction inlet at a large collision angle. Some particles leaked out of other inlet surfaces due to their inertia, even after being inhaled (see Figure 13). This phenomenon was consistent with that reported in Reference [14]. Secondly, the gradually increasing vehicle speed also made the load ratio of the particles increase, which resulted in the dust suction performance being lower.

Figure 14 illustrates the influence of traveling speed on the grade dust-collection efficiency. For a given particle traveling speed, the grade dust-collection efficiency decreased when the particle size increased from $45 \mu \mathrm{m}$ to $152 \mu \mathrm{m}$ (for example, a traveling speed of $14 \mathrm{~km} / \mathrm{h}$ corresponded to a $13.19 \%$ decrease). Similarly, for the same particle size, the grade dust-collection efficiency decreased with increasing traveling speed. The most significant drop (from $94.32 \%$ to $70.51 \%$ ) occurred for particle sizes ranging from $5 \mathrm{~km} / \mathrm{h}$ to $14 \mathrm{~km} / \mathrm{h}$, and a given particle diameter of $152 \mu \mathrm{m}$. It was observed that a lower driving speed was beneficial, and that the traveling speed could be appropriately increased if there were few particles on the ground. 


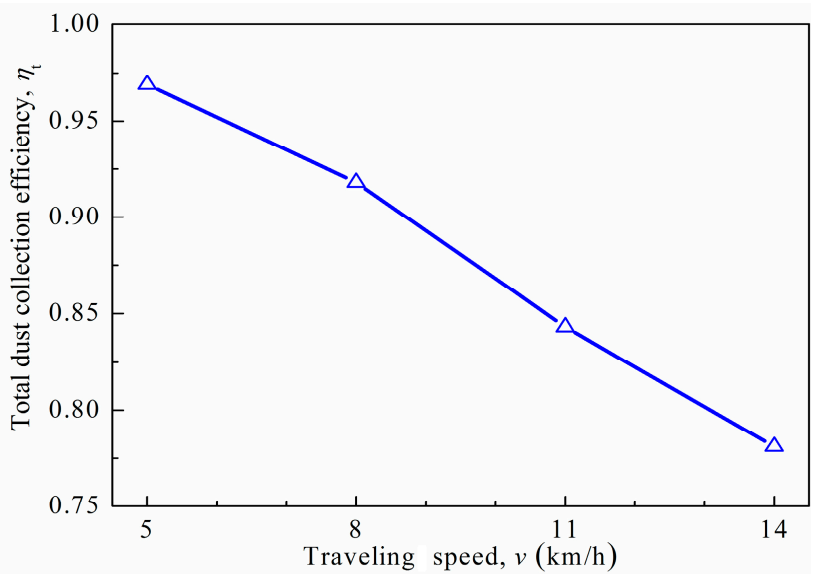

Figure 12. Influence of traveling speed on the separation efficiency.

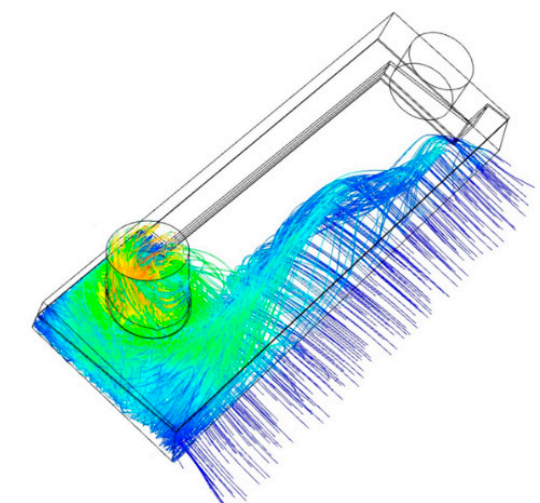

(a) $v=5 \mathrm{~km} / \mathrm{h}$

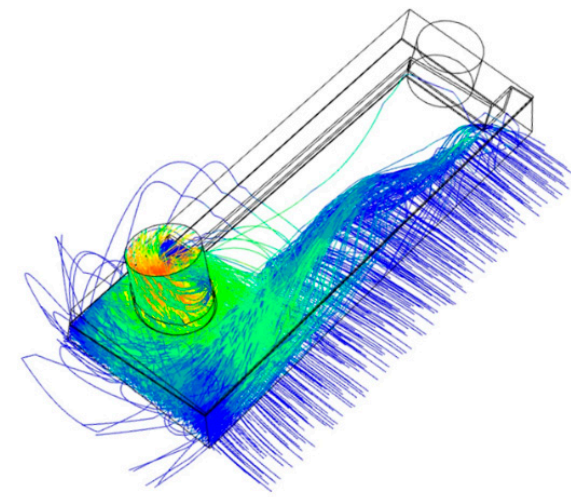

(b) $v=14 \mathrm{~km} / \mathrm{h}$ Velocity Magnitude

$\begin{array}{lll}0.00 & 6.28 & 12.56\end{array}$ $[\mathrm{m} / \mathrm{s}$ ]

Figure 13. Particle velocities and trajectories under different traveling speeds: (a) traveling speed is $5 \mathrm{~km} / \mathrm{h}$; (b) traveling speed is $14 \mathrm{~km} / \mathrm{h}$.

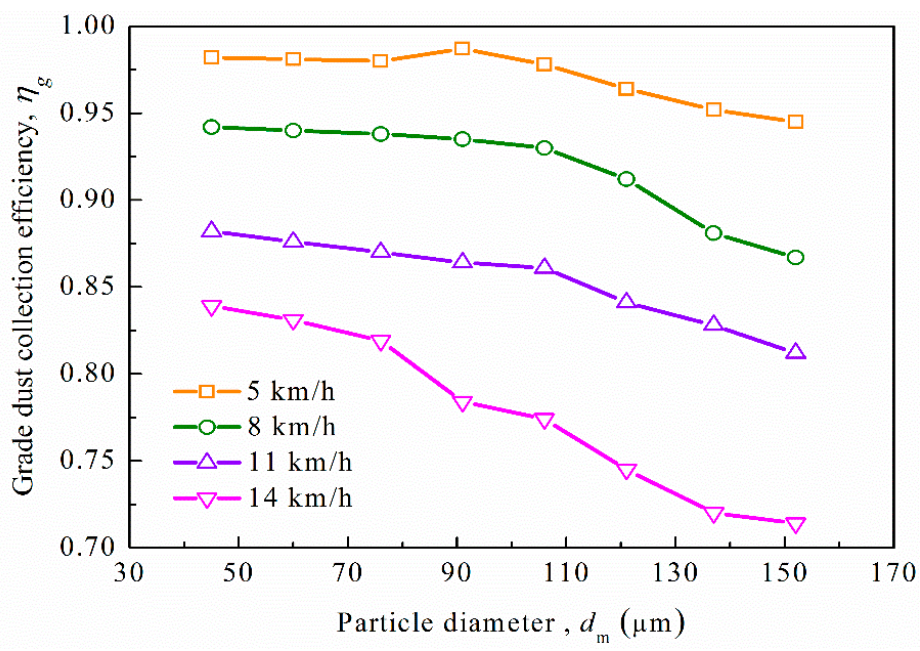

Figure 14. Influence of traveling speed on the grade dust-collection efficiency.

Figure 15 illustrates the influence of traveling speed on the average retention time. For a given particle traveling speed, the average retention time increased when the particle size increased from 
$45 \mu \mathrm{m}$ to $152 \mu \mathrm{m}$ (for example, a traveling speed of $5 \mathrm{~km} / \mathrm{h}$ corresponded to a $0.189 \mathrm{~s}$ increase). Similarly, for the same particle size, the average retention time increased with increasing traveling speed. The most significant improvement (from $0.421 \mathrm{~s}$ to $0.344 \mathrm{~s}$ ) occurred for traveling speeds ranging from $5 \mathrm{~km} / \mathrm{h}$ to $14 \mathrm{~km} / \mathrm{h}$, and a given particle diameter of $152 \mu \mathrm{m}$. The increase of the traveling speed was not conducive to improvement of the efficiency. Therefore, the speed should be selected reasonably.

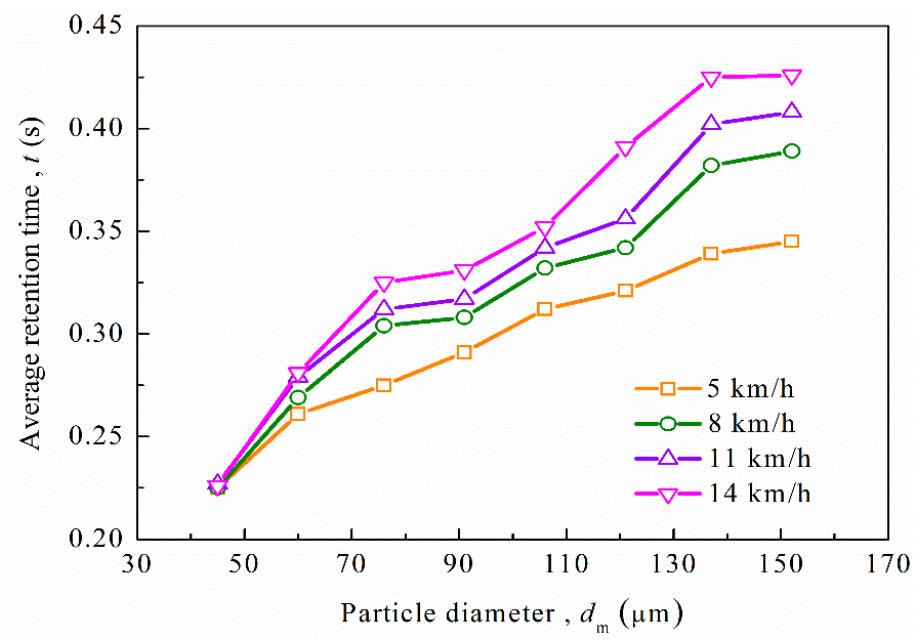

Figure 15. Influence of traveling speed on the average retention time.

\section{Uniform Design and Statistical Analysis}

Experiment Design and Multiple Regression Model Building

Uniform design (UD) and multiple regression analysis (MRA) were used in prediction and optimization of particle separation under variable operational conditions. The reverse-blowing flow rate, pressure drop, and traveling speed were evaluated. As shown in Table 3, the criteria of a U12 $\left(4^{3}\right)$ uniform design table were applied.

Table 3. Factor Level Table of Operational Parameters and Experimental Results.

\begin{tabular}{ccccc}
\hline NO. & $\begin{array}{c}\mathbf{x}_{\mathbf{1}} \\
\text { Reverse Blowing Flow } \\
\text { Rate }\left(\mathbf{m}^{\mathbf{3}} \mathbf{h} \mathbf{h}\right)\end{array}$ & $\begin{array}{c}\mathbf{x}_{\mathbf{2}} \\
\text { Traveling Speed } \\
\mathbf{( k m / h )}\end{array}$ & $\begin{array}{c}\mathbf{x}_{\mathbf{3}} \\
\text { Pressure Drop (Pa) }\end{array}$ & $\begin{array}{c}\mathbf{y} \\
\text { Particle-Separation } \\
\text { Efficiency } \mathbf{( \% )}\end{array}$ \\
\hline 1 & 2570 & 8 & 1900 & 66.03 \\
2 & 2570 & 14 & 2900 & 80.79 \\
3 & 3120 & 14 & 1900 & 3.23 \\
4 & 3120 & 5 & 2900 & 59.23 \\
5 & 2073 & 8 & 2400 & 94.34 \\
6 & 1550 & 11 & 2900 & 94.73 \\
7 & 2073 & 5 & 1400 & 96.74 \\
8 & 3120 & 8 & 1400 & 2.41 \\
9 & 1550 & 5 & 2400 & 99.13 \\
10 & 2570 & 11 & 2400 & 78.78 \\
11 & 2073 & 11 & 1900 & 83.24 \\
12 & 1550 & 14 & 1400 & 70.32 \\
\hline
\end{tabular}

During the optimization process, the response variables were fitted by a quadratic model, as shown in Equation (10).

$$
y=b_{0}+\sum_{i=1}^{n} b_{i} x_{i}+\sum_{i=1}^{n} b_{i i} x_{i}^{2}+\sum_{i<j} b_{i j} x_{i} x_{j}
$$


where $y$ is predicted response value, $n$ is number of factors, $x_{i}$ is influence factor. $b_{0}, b_{i i}$, and $b_{i j}$ are constant term, quadratic, and interaction term coefficients, respectively.

The resulting ternary quadratic regression equation was obtained via stepwise regression method (Equation (11)), and it described the particle-separation efficiency relative to the reverse-blowing flow rate, pressure drop, and traveling speed as

$$
\begin{gathered}
y_{1}=619.66298-0.28623 x_{1}+4.75292 x_{2}-0.17401 x_{3}+0.00001 x_{1}{ }^{2}-1.50795 x_{2}{ }^{2} \\
-0.00001 x_{3}{ }^{2}+0.00311 x_{1} x_{2}+0.00007 x_{1} x_{3}+0.00658 x_{2} x_{3}
\end{gathered}
$$

After the multiple linear regression equation of the operational parameters was established, the significance of the equation was determined using an $F$-test $[27,28]$. Table 4 shows the variance analysis of the operational-parameter linear regression equation. $F_{0.05(9,2)}=19.38<269.01$, which indicated that the ternary quadratic regression was significant.

Table 4. Variance Analysis of Linear Regression Equation Composed of Operational Parameters.

\begin{tabular}{ccccc}
\hline Source of Variance & Degree of Freedom & Quadratic Sum of Deviation & Variance & F-Value \\
\hline Regression & 9 & $12,274.63$ & 1363.85 & 269.01 \\
Partial regression & 2 & 10.14 & 5.07 & \\
Total & 11 & $12,284.77$ & & \\
\hline
\end{tabular}

The significance of each coefficient was determined using a $t$-test [29-31], and is listed in Table 5. $t_{\mathrm{bi}}(\mathrm{i}=1,2,3 \ldots \mathrm{m})$ is partial regression coefficient. The partial regression coefficient $b_{8}$ had the most significant impact on the regression equation because of $\left|t_{b_{8}}\right|>t_{0.05(2)}\left(t_{0.05(2)}=4.303\right)$ only. The negligible regression coefficients were eliminated until both the equation and partial regression coefficients satisfied the requirements. Furthermore, each regression equation needed to be re-established after eliminating an independent variable. The regression equation was obtained after five reconstitutions:

$$
y_{2}=-87.98913690+0.17992545 x_{1}-0.00004963 x_{1}^{2}-0.00099563 x_{1} x_{2}+0.00000919 x_{1} x_{3}
$$

Table 5. $t$-Statistics.

\begin{tabular}{ccccccccc}
\hline $\boldsymbol{t}_{\boldsymbol{b}_{1}}$ & $\boldsymbol{t}_{\boldsymbol{b}_{2}}$ & $\boldsymbol{t}_{\boldsymbol{b}_{3}}$ & $\boldsymbol{t}_{\boldsymbol{b}_{4}}$ & $\boldsymbol{t}_{\boldsymbol{b}_{5}}$ & $\boldsymbol{t}_{\boldsymbol{b}_{6}}$ & $\boldsymbol{t}_{\boldsymbol{b}_{7}}$ & $\boldsymbol{t}_{\boldsymbol{b}_{8}}$ & $\boldsymbol{t}_{\boldsymbol{b}_{9}}$ \\
\hline 2.8036 & 0.8914 & 2.5053 & 0.9289 & 3.1875 & 0.3596 & 1.4883 & 5.3905 & 2.9637 \\
\hline
\end{tabular}

The parameter degree of influence was determined via standardization of the regression coefficients (Table 6). These coefficients were written in descending order of this influence, after absolute values of the standardized regression coefficients, i.e., $x_{1}^{2}>x_{1}>x_{1} x_{3}>x_{1} x_{2}$. The maximum value was realized for the following operational-parameter combination: reverse-blowing flow rate $x_{1}=2075 \mathrm{~m}^{3} / \mathrm{h}$, traveling speed $\mathrm{x}_{2}=5 \mathrm{~km} / \mathrm{h}$, and pressure drop $\mathrm{x}_{3}=2403 \mathrm{~Pa}$.

Table 6. Standardization of Regression Analysis Coefficients.

\begin{tabular}{ccccc}
\hline & $\mathbf{x}_{\mathbf{1}}$ & $\mathbf{x}_{\mathbf{1}}{ }^{\mathbf{2}}$ & $\mathbf{x}_{\mathbf{1}} \mathbf{x}_{\mathbf{2}}$ & $\mathbf{x}_{\mathbf{1}} \mathbf{x}_{\mathbf{3}}$ \\
\hline Regression coefficient & 0.17992545 & -0.00004963 & -0.00099563 & 0.00000919 \\
Standardized result & 3.2743 & -4.2421 & -0.3046 & 0.5277 \\
\hline
\end{tabular}

\section{Verification and Site Test for Total Dust-Collection Efficiency}

An additional experiment was necessary because experiments using this combination had not been included. Considering that the operational parameters were set to round up and down, the 3D 
model was designated as: reverse-blowing flow rate $x_{1}=2100 \mathrm{~m}^{3} / \mathrm{h}$, traveling speed $\mathrm{x}_{2}=5 \mathrm{~km} / \mathrm{h}$, and pressure drop $x_{3}=2400 \mathrm{~Pa}$. The location distribution of measurement points is shown in Figure 16, and the measurement points were $20 \mathrm{~mm}$ above the ground surface (see Figure 16).

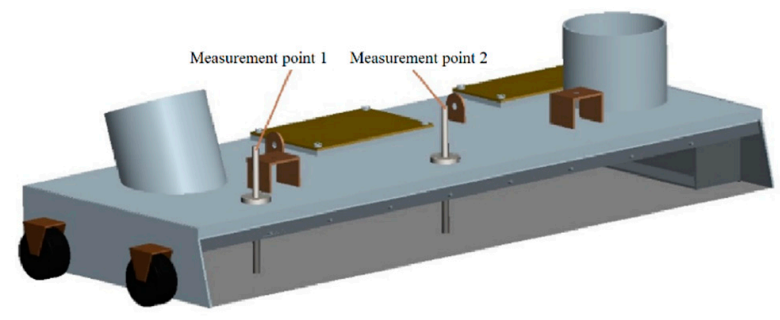

Figure 16. Location distribution of measurement point.

The site test was carried out at a school. A centrifugal blower and axial fan were employed to produce positive and negative pressure, respectively (Figure 17a). The pressure and flow rate could be adjusted according to the speed of the motor. The experiment was conducted after the centrifugal blower and axial fun were operating stably. The Kasda-KV621 hot-wire anemometer (Tianjin Kasda Instruments Co., Ltd, Tianjin, China) was used to measure the velocity within the vacuum-blowing cleaning system. A notebook running a Vib'SYS program was connected to a charge amplifier and a data-acquisition instrument in order to collect the data. The data-acquisition instrument was a WS-5921/U60232 (Beijing Wavespectrum Science \& Technology Co., Ltd., Beijing, China). The test system was as shown in Figure 17b.

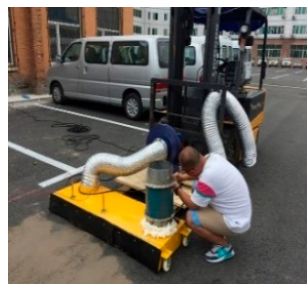

(a)

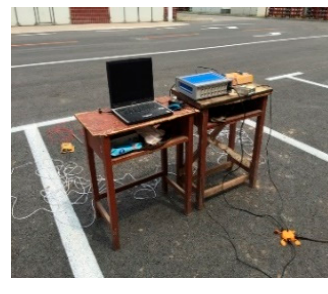

(b)

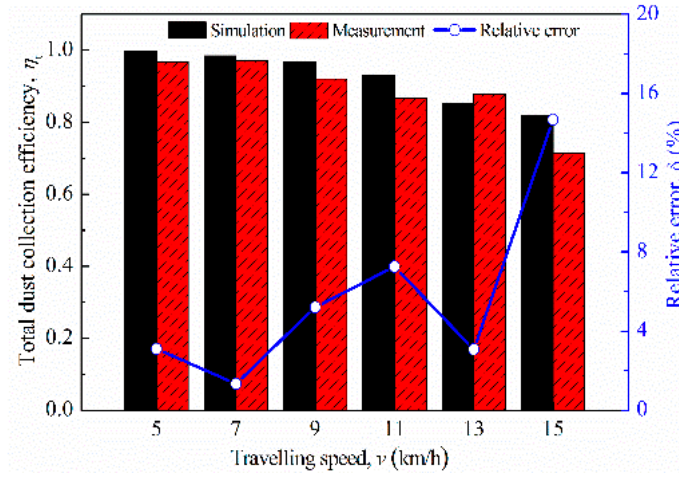

(c)

Figure 17. Site test for total dust-collection efficiency: (a) site test (b) test system (c) test results contrast analysis

The test road surface was covered uniformly with dust particles (distribution density: $0.15 \mathrm{~kg} / \mathrm{m}^{2}$ ). We collected the particles for the experiment from a tertiary highway according to Reference [14]. We could not track the particles to find the trajectory in the mechanical equipment, but we used a quality dust-weighing method and velocity calibration for test validation. The mass-calculation method was used. The dust-collection efficiency was determined by calculating the mass of ground particles before and after dust-collection. Figure 17c shows the contrast analysis of different traveling speeds and total dust-collection efficiency test results. There existed a good agreement of the CFD numerical calculation with the experimental data. The simulation data were on the whole higher than the measured ones. The reason was that the situation in the CFD simulation was ideal without any leakage, and provided better air-tightness. In addition, there was an error introduced by weighing dust manually. The average relative error of the total dust-collection efficiency was $6.53 \%$, which satisfied the value of $10 \%$ [14,32-34]. The similarity with the numerical parameter was checked.

The forklift moved at a speed of $5 \mathrm{~km} / \mathrm{h}$ or $10 \mathrm{~km} / \mathrm{h}$. A Kasda-KV621 hot-wire anemometer (Tianjin Kasda Instruments Co., Ltd., Tianjin, China) was employed. By comparing the experimental and 
simulation data (see Figure 18), it was found that the value of the No. 1 measuring point was higher than that of No. 2. This is because the No. 1 measuring point was closer to the suction inlet, which resulted in its higher velocity. The simulation data were a little higher than experimental ones, which indicated that the results of the CFD simulation analysis were authentic. The main reasons for the deviation can be summarized as follows. For one thing, the dust particle models were different, so the particle trajectories were different with localization errors, which led to a statistical error for a large quantity of particles in the suction inlet. Furthermore, the situation in the CFD simulation was ideal, without the leakage of air, while the vacuum-blowing cleaning system was bound to be not air-tight and to have pressure loss occur. These factors may have made the experimental data lower than simulation data.

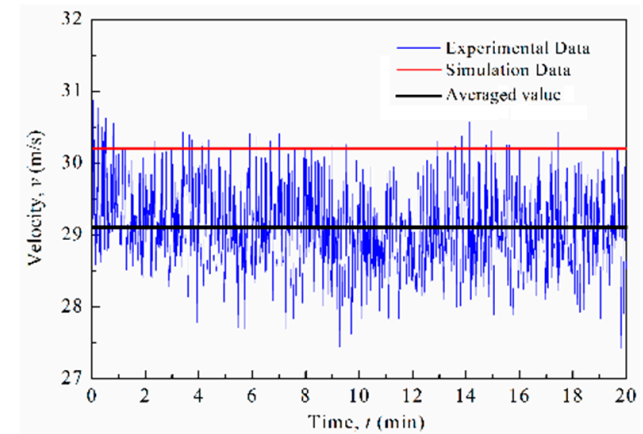

(a)

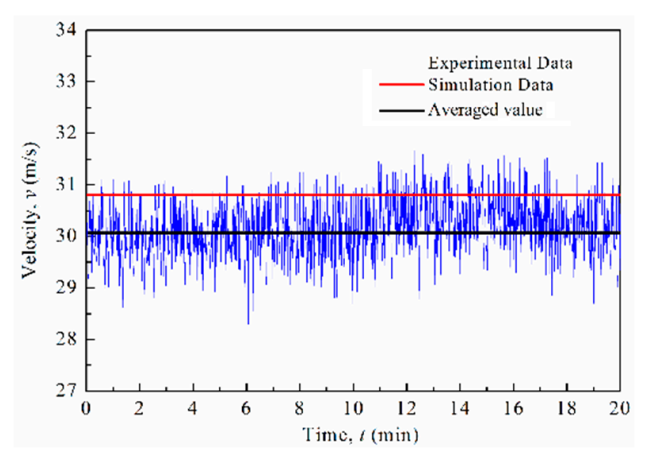

(c)

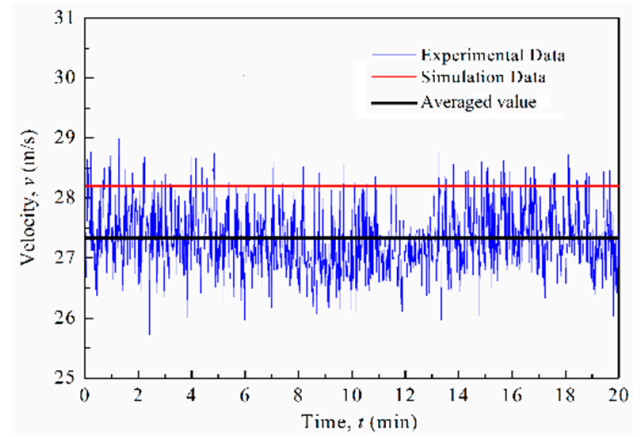

(b)

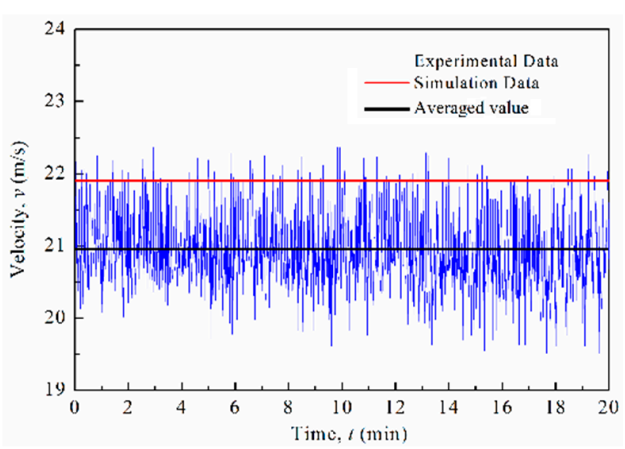

(d)

Figure 18. Comparison of experimental and simulation data: (a) Measurement point $1, v_{\mathrm{t}}=5 \mathrm{~km} / \mathrm{h}$; (b) Measurement point 2, $v_{\mathrm{t}}=5 \mathrm{~km} / \mathrm{h}$; (c) Measurement point 1, $v_{\mathrm{t}}=10 \mathrm{~km} / \mathrm{h}$; (d) Measurement point 2, $v_{\mathrm{t}}=10 \mathrm{~km} / \mathrm{h}$

\section{Conclusions}

The operational parameters of reverse-blowing flow rate, pressure drop, and traveling speed all influenced the particle-separation performance. The total dust-collection performance first increased and then decreased with increasing reverse-blowing flow rate. $Q=2172 \mathrm{~m}^{3} / \mathrm{h}$ was a turning point. The total dust-collection efficiency increased gradually from $69.20 \%$ to $97.35 \%$, and then it decreased sharply from $97.35 \%$ to $16.31 \%$. Furthermore, the dust-collection efficiency increased when the pressure drop increased. The efficiency increased from $68.11 \%$ to $86.15 \%$ when the pressure changed from 1400 to $2000 \mathrm{~Pa}$. However, the total dust-collection efficiency did not change significantly when the pressure drop was finally increased from 2600 to $2900 \mathrm{~Pa}$. In contrast, the total dust-collection efficiency decreased when the traveling speed increased. The total dust-collection efficiency decreased from $96.97 \%$ to $79.01 \%$ when the speed changed from $5 \mathrm{~km} / \mathrm{h}$ to $14 \mathrm{~km} / \mathrm{h}$.

UD and MRA methods were adopted to predict and optimize the operational parameters. As far as particle-separation performance is concerned, the descending order of their influence was $x_{1}^{2}>x_{1}>x_{1} x_{3}>x_{1} x_{2}$. The maximum particle-separation efficiency was $99.10 \%$, and it was realized 
under the following conditions: reverse-blowing flow rate: $2100 \mathrm{~m}^{3} / \mathrm{h}$, traveling speed: $5 \mathrm{~km} / \mathrm{h}$, and pressure drop: $2400 \mathrm{~Pa}$. The simulation results, including the velocities in the vacuum-blowing cleaning system and particle-separation performance, are in good agreement with the experimental data. The average relative error of the total dust-collection efficiency was $6.53 \%$, which meets the requirements for a wide range of applications.

Author Contributions: Conceptualization, Y.X., Y.D. and X.-1.Z.; methodology, Y.X.; software, Y.X. and X.-1.Z.; validation, Y.X., Y.D. and X.Z.; formal analysis, Y.D.; investigation, X.Z.; resources, X.-1.Z.; data curation, Y.X.; writing—original draft preparation, Y.X.; writing—review and editing, Y.X.; visualization, Y.D.; supervision, X.Z.; project administration, X.Z.; funding acquisition, Y.X., Y.D. and X.-1.Z. All authors have read and agreed to the published version of the manuscript.

Funding: This research was funded by China Postdoctoral Science Foundation (2020M672084, 2018M631167); Natural Science Foundation of Liaoning Province (20180550816, 20180550079); National Natural Science Foundation of China (21706023, 51806114, 51874187).

Acknowledgments: The authors are grateful to the foundations for their support.

Conflicts of Interest: The authors declare no conflict of interest.

\section{Nomenclature}

$B$

$H$

$D_{1}$

$D_{2}$

$\mathrm{y}^{+}$

TKE prandtl number

TDR prandtl number

Energy prandtl number

Wall prandtl number

$C_{\mathrm{mu}}$

$\mathrm{C}_{1 \varepsilon}$

$C_{2 \varepsilon}$

$q_{\mathrm{m}}$

$d_{\mathrm{m}}$

$n$

$\mathrm{x}_{\mathrm{i}}$

$\mathrm{y}_{\mathrm{i}}$

$b_{0}$

$b_{i i}$

$b_{i j}$

$t$

$Q_{\mathrm{R}}$

\section{Greek Letters}

$\alpha$

$\beta$

$\delta$

$\delta_{\varepsilon}$

$\rho_{\mathrm{g}}$

$\rho_{\mathrm{p}}$

$\rho_{\mathrm{d}}$

$e_{\text {normal }}$

$e_{\text {tangential }}$

$\eta_{\mathrm{t}}$

$\eta \mathrm{g}$ width, mm

thickness, $\mathrm{mm}$

suction inlet diameter, $\mathrm{mm}$

reverse- jet diameter, $\mathrm{mm}$

wall distance

1 , constant

1.3 , constant

0.85 , constant

0.85 , constant

0.89 , constant

1.46 , constant

1.89 , constant

total flow rate, $\mathrm{kg} \cdot \mathrm{s}^{-1}$

particle mean diameter, $\mu \mathrm{m}$

spread parameter,

influence factor

predicted response value, $\%$

constant term

quadratic term coefficient

interaction term coefficient

average retention time, $\mathrm{s}$

reverse blowing flow rate, $\mathrm{m}^{3} / \mathrm{h}$

front damper angle, ${ }^{\circ}$

suction inlet inclination angle, ${ }^{\circ}$

ground clearance, $\mathrm{mm}$

1.4, constant

gas density, $\mathrm{kg} \cdot \mathrm{m}^{-3}$

particle density, $\mathrm{kg} \cdot \mathrm{m}^{-3}$

particle density, $\mathrm{kg} \cdot \mathrm{m}^{-3}$

normal restitution coefficient

tangential restitution coefficient

total dust-collection efficiency, $\%$

grade dust-collection efficiency, \% 


\section{References}

1. Wang, J.S.; Huang, J.J.; Li, J. Characterization of the pollutant build-up processes and concentration/mass load in road deposited sediments over a long dry period. Sci. Total Environ. 2020, 718, 12. [CrossRef] [PubMed]

2. Amato, F.; Pandolfi, M.; Viana, M.; Querol, X.; Alastuey, A.; Moreno, T. Spatial and chemical patterns of PM10 in road dust deposited in urban environment. Atmos. Environ. 2009, 43, 1650-1659. [CrossRef]

3. Gao, J.H.; Woodward, A.; Vardoulakis, S.; Kovats, S.; Wilkinson, P.; Li, L.P.; Xu, L.; Li, J.; Yang, J.; Li, J.; et al. Haze, public health and mitigation measures in China: A review of the current evidence for further policy response. Sci. Total Environ. 2017, 578, 148-157. [CrossRef] [PubMed]

4. Hassan, A.; Latif, M.T.; Soo, C.I.; Faisal, A.H.; Roslina, A.M.; Andrea, Y.L.B.; Hassan, T. Short communication: Diagnosis of lung cancer increases during the annual southeast Asian haze periods. Lung Cancer 2017, 113, 1-3. [CrossRef]

5. Yun, Y.; Gao, R.; Yue, H.F.; Guo, L.; Li, G.K.; Sang, N. Sulfate Aerosols Promote Lung Cancer Metastasis by Epigenetically Regulating the Epithelial-to-Mesenchymal Transition (EMT). Environ. Sci. Technol. 2017, 51, 11401-11411. [CrossRef]

6. Chen, Z.J.; Wu, X.Y.; Xu, G.P.; Wang, A.Q. Experimental Study on Suction Mouth of Vacuum Sweeper. J. Tongji Univ. 2001, 29, 1483-1485.

7. Daichin; Lee, S.J. Experimental analysis of flow fields inside intake heads of a vacuum cleaner. J. Mech. Sci. Technol. 2005, 19, 894-904. [CrossRef]

8. Bofu, W.; Jinlai, M.; Jie, C. Study of the Particle Separation Performance of a Dust-settling Hopper. Chem. Prod. Process Mod. 2011, 6, 27. [CrossRef]

9. Avsar, E.; Hanedar, A.; Toroz, I.; Alp, K.; Kaynak, B. Investigation of PM10 Concentrations and Noise Levels of the Road Sweepers Operating in Istanbul-Turkey: A Case Study. Fresenius Environ. Bull. 2010, 19, 2033-2039.

10. Zeng, G.-y.; Li, X.-f.; Xiao, T.-y.; Xu, Y. Simulation for the design of dust suction system of highway sweeper. J. Syst. Simul. 2004, 16, 2770-2773.

11. Xu, Y.; Li, X.-f.; Xiao, T.-y.; Zeng, G.-y. Research on applications of computational dynamic fluid in the simulation analysis of highway mechanical sweeper. J. Syst. Simul. 2004, 16, 270-273.

12. Aoki, P.M.; Honicky, R.J.; Mainwaring, A.; Myers, C.; Paulos, E.; Subramanian, S.; Woodruff, A. A Vehicle for Research: Using Street Sweepers to Explore the Landscape of Environmental Community Action; 27th Annual CHI Conference on Human Factors in Computing Systems; ACM Press: New York, NY, USA, 2009; pp. 375-384.

13. Wu, B.; Men, I.; Chen, I. Improving the design of a pickup head for particle removal using computational fluid dynamics. Proc. Inst. Mech. Eng. Part C-J. Eng. Mech. Eng. Sci. 2011, 225, 939-948. [CrossRef]

14. Wu, B.F.; Men, J.L.; Chen, J. Numerical study on particle removal performance of pickup head for a street vacuum sweeper. Powder Technol. 2010, 200, 16-24. [CrossRef]

15. Liu, X.; Zhang, Y.; Liu, F.; Wu, Q.; Zhang, M.; Guo, Y. Structure design and flow field simulation analysis of a dust collector based on tornado principle. Harbin Gongye Daxue Xuebao/J. Harbin Inst. Technol. 2020, 52, 106-114. [CrossRef]

16. Xi, Y.; Cheng, K.; Li, G.-X.; Cheng, L. Effect of Front Baffle Inclination Angle and Pressure Drop on Absorption Performance of a Pickup Mouth. J. Donghua Univ., Engl. Ed. 2016, 33, 8-12.

17. Xi, Y.; Cheng, K.; Lou, X.-t.; Cheng, L.; Dong, C. Numerical Simulation of Gas-Solid Two-Phase Flow in Reverse Blowing Pickup Mouth. J. Donghua Univ., Engl. Ed. 2015, 32, 530-535.

18. He, Y.; Deen, N.G.; van Sint Annaland, M.; Kuipers, J.A.M. Gas-Solid Turbulent Flow in a Circulating Fluidized Bed Riser: Experimental and Numerical Study of Monodisperse Particle Systems. Ind. Eng. Chem. Res. 2009, 48, 8091-8097. [CrossRef]

19. Guo, Y.; Stevanovic, S.; Verma, P.; Jafari, M.; Jabbour, N.; Brown, R.; Cravigan, L.; Alroe, J.; Osuagwu, C.G.; Brown, R.; et al. An experimental study of the role of biodiesel on the performance of diesel particulate filters. Fuel 2019, 247, 67-76. [CrossRef]

20. Saffman, P.G. The lift on a small sphere in a slow shear flow. J. Fluid Mech. 1965, 22, 385-400. [CrossRef]

21. Li, A.; Ahmadi, G. Dispersion and deposition of spherical particles from point sources in a turbulent channel flow. Aerosol Sci. Technol. 1992, 16, 209-226. [CrossRef]

22. Zhang, Y.C.; Yang, C.Z.; Baker, C.; Chen, M.; Zou, X.; Dai, W.L. Effects of expanding zone parameters of vacuum dust suction mouth on flow simulation results. J. Cent. South Univ. 2014, 21, 2547-2552. [CrossRef] 
23. Ludwig, W.; Pluszka, P. Euler-Lagrange model of particles circulation in a spout-fluid bed apparatus for dry coating. Powder Technol. 2018, 328, 375-388. [CrossRef]

24. Ludwig, W.; Pluszka, P. The analysis of the influence of the normal restitution coefficient model on calculated particles velocities by means of Eulerian-Lagrangian approach. Powder Technol. 2019, 344, 140-151. [CrossRef]

25. Chuah, T.G.; Gimbun, J.; Choong, T.S.Y. A CFD study of the effect of cone dimensions on sampling aerocyclones performance and hydrodynamics. Powder Technol. 2006, 162, 126-132. [CrossRef]

26. Othman, S.R.; Yahaya, N.; Noor, N.M.; Sing, L.K.; Zardasti, L.; Rashid, A.S.A. Modeling of External Metal Loss for Corroded Buried Pipeline. J. Press. Vessel Technol.-Trans. ASME 2017, 139, 12. [CrossRef]

27. Ping, H.L.; Xu, G.H.; Wu, S.F. System optimization of cyclohexane dehydrogenation under multiphase reaction conditions using the uniform design method. Int. J. Hydrog. Energy 2015, 40, 15923-15932. [CrossRef]

28. Xu, Q.S.; Xu, Y.D.; Li, L.; Fang, K.T. Uniform experimental design in chemometrics. J. Chemometr. 2018, 32, 10. [CrossRef]

29. Chen, W.Y.; Yang, J.; Chen, Z.Y.; Luo, F.Y.; Wu, C.L.; Peng, Z.S. Predicting photosynthetic rate of sunflowers using back propagation neural network based on uniform design. Afr. J. Agric. Res. 2011, 6, 5817-5821. [CrossRef]

30. Fang, F.; Zang, G.L.; Sun, M.; Yu, H.Q. Optimizing multi-variables of microbial fuel cell for electricity generation with an integrated modeling and experimental approach. Appl. Energy 2013, 110, 98-103. [CrossRef]

31. Zhou, X.P.; Huang, X.C.; Liu, P.F.; Li, T.F. A probabilistic method to analyze collapse failure of shallow rectangular tunnels. Tunn. Undergr. Space Technol. 2018, 82, 9-19. [CrossRef]

32. Zhu, G.R.; Tan, W.; Yu, Y.; Liu, L.Y. Experimental and Numerical Study of the Solid Concentration Distribution in a Horizontal Screw Decanter Centrifuge. Ind. Eng. Chem. Res. 2013, 52, 17249-17256. [CrossRef]

33. Bunyawanichakul, P.; Kirkpatrick, M.P.; Sargison, J.E.; Walker, G.J. Numerical and experimental studies of the flow field in a cyclone dryer. J. Fluids Eng.-Trans. ASME 2006, 128, 1240-1250. [CrossRef]

34. Luan, Y.G.; Sun, H.O. Experimental and Numerical Study on the Resistance Performance of an Axial Flow Cyclone Separator. Math. Probl. Eng. 2015, 1-9. [CrossRef]

(C) 2020 by the authors. Licensee MDPI, Basel, Switzerland. This article is an open access article distributed under the terms and conditions of the Creative Commons Attribution (CC BY) license (http://creativecommons.org/licenses/by/4.0/). 